Revista de Comunicación y Salud, 2020, Vol. 10, oㅡ 2, pp. 355-384

Editado por Cátedra de Comunicación y Salud

ISSN: 2173-1675

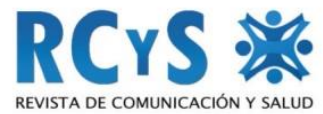

Enviado 15/08/2020

Aprobado 03/09/2020

\title{
LA COVID-19 EN LA PRENSA ESPAÑOLA. ENCUADRES DE ALARMA Y TRANQUILIDAD EN LAS PORTADAS DE EL PAÍS, EL MUNDO Y LA VANGUARDIA.
}

\author{
Covid-19 in the spanish press. Framing alarm and reassurance on the front pages \\ of EI País, El Mundo and La Vanguardia
}

\author{
Laura Picazo Sánchez \\ Universidad Internacional de Valencia. España. \\ lpicazo@universidadviu.com \\ Belinda de Frutos Torres \\ Universidad de Valladolid. España. \\ belinda.defrutos@hmca.uva.es \\ Alfonso Gutiérrez Martín \\ Universidad de Valladolid. España. \\ alfonso.gutierrez.martin@uva.es
}

Financiación. Financiado por el Proyecto Internética. Proyecto $1+D+i$ subvencionado por el MCINN (PID 2019-104689RB-100). Fecha de inicio: 1 de junio 2020. Fecha de fin: 1 de junio 2023

\section{Resumen}

Se presenta un análisis de las noticias incluidas en portada por los tres medios más leídos en España (El país, El mundo y La vanguardia) durante el estado de alarma y la situación de confinamiento por la Covid-19 en los meses de marzo y abril de 2020. El principal objetivo del estudio es analizar si los citados medios han trasladado los hechos noticiosos a través de mensajes de alarma 0 de tranquilidad aparentemente injustificados. En la introducción se analiza el papel de los medios de comunicación convencionales, los medios digitales y las redes sociales en períodos de pandemia, así como los posibles marcos de interpretación (framing) en la cobertura de la crisis. Se han revisado 1.154 noticias de portada e identificado para el análisis 419 elementos, pertenecientes a 162 hechos noticiosos comunes, publicados al menos en dos de los tres diarios analizados que conforman la muestra de este estudio. El instrumento de análisis está basado en herramientas de medición de framing ya validadas y empleadas en numerosos artículos de referencia. Los resultados muestran que el tratamiento de la información en clave de alarma y tranquilidad no obedece tanto a la objetividad de los hechos noticiosos relatados ni a razones sanitarias, como a intereses políticos a favor 0 en contra del Gobierno u otros intereses. Se concluye que, dada la importancia de los medios de comunicación durante las pandemias, tanto en la creación de la realidad 
La COVID-19 en la prensa española. Encuadres de alarma y tranquilidad en las portadas de El País, El Mundo y La Vanguardia

percibida como en la valoración de su gravedad, sus responsables deben ser conscientes de la responsabilidad social y función educativa de la comunicación. Para conseguir una información veraz y de servicio público se plantean como necesarias la independencia económica de los medios y la formación en educación mediática de sus profesionales.

\title{
Palabras clave:
}

Medios de comunicación, Covid-19, framing, sesgo informativo, alarma, prensa española, fines políticos.

\begin{abstract}
An analysis of the news included on the front page of the three most read media in Spain (El país, El mundo and La vanguardia) during the state of alarm and the COVID19 confinement situation in the months of March and April 2020 is presented. The main objective of the study is to analyze whether the aforementioned media have conveyed the news events through seemingly unjustified messages of alarm or reassurance. The introduction analyses the role of conventional media, digital media and social networks in periods of pandemic, as well as framing in the coverage of the crisis. A total of 1,154 front page stories have been reviewed and 402 elements (belonging to 162 shared news events and another 35 not shared news events) have been identified for analysis. These constitute the sample for this study. The analysis tool is based on already validated framing measurement tools used in numerous leading articles. The results show that the treatment of information in terms of alarm and reassurance is not so much based on the objectivity of the news events reported or on health reasons, but rather on political interests in favour of or against the government or other interests. It is concluded that, given the importance of the media during pandemics both in the creation of perceived reality and in the assessment of its seriousness, media managers should be aware of the social responsibility and educational function of communication. In order to achieve truthful and public service information, the economic independence of the media and the training of its professionals in media education are considered necessary.
\end{abstract}

Keywords: Media, Covid-19, framing theory, information bias, alarm, Spanish press, political purposes, social responsibility, disinformation.

\section{Cómo crear el artículo}

Picazo Sánchez, L., de Frutos Torres, B. y Gutiérrez Martín, A. (2020). La COVID-19 en la prensa española. Encuadres de alarma y tranquilidad en las portadas de El País, El Mundo y La Vanguardia. Revista de Comunicación y Salud, 10 (2), 355-384. doi: https://doi.org/10.35669/rcys.2020.10(2).355-384

\section{INTRODUCCIÓN}

La distribución de prensa ha sido considerada como un servicio esencial que contribuye a la solución de la actual pandemia del Covid-19. Expertos en Infectología y 
La COVID-19 en la prensa española. Encuadres de alarma y tranquilidad en las portadas de El País, El Mundo y La Vanguardia

Epidemiología consideran que la herramienta más poderosa de prevención es la información, y apelan a los medios de comunicación para compartirla de manera correcta y responsable (Hernández-Orozco, Ramiro-Mendoza y Trejo-González, 2020).

La comunicación con el público y la necesidad de disponer de información veraz y contrastada, avalada por fuentes fiables es, en situaciones de pandemia, más necesaria que nunca. Así se ha puesto de manifiesto por la OMS en esta y anteriores crisis sanitarias, como la de gripe en 2009. La Organización Panamericana de la Salud, en referencia a la pandemia de influenza 2009 señala: "Los medios pueden condicionar tanto las agendas como las decisiones de gobiernos y agencias de cooperación. [...] De igual forma, constituyen un instrumento de crítica y denuncia cuando se intuyen irregularidades o se carece de transparencia y responsabilidad en el manejo de la emergencia (Arroyo-Barrantes et al, 2009: 62).

En el caso de la Covid-19, la OMS también ha considerado primordial la colaboración entre las autoridades sanitarias y los medios de comunicación (WHO, 2020), pero como elemento diferenciador con respecto a anteriores pandemias hay que considerar el actual panorama mediático de convergencia y continua transformación. Al potencial de los medios convencionales hay que sumar la singularidad de los medios digitales y la influencia de las redes sociales, así como la consecuente proliferación de bulos y fake news.

La comunidad científica internacional ha reaccionado rápida y positivamente, y no solo en el campo de la medicina. Desde otras áreas también se intenta generar el conocimiento necesario para lograr la mejor salida posible de la crisis en todas sus dimensiones: personales, sociales y económicas. Rapidez que no está exenta de riesgos ya que con la premura se posibilita la difusión de soluciones sanitarias no suficientemente contrastadas (Lariviére et al, 2020).

En el campo de la comunicación y el periodismo el desafío en torno a la pandemia es triple: informar verazmente sobre los acontecimientos y los resultados de la investigación sanitaria; investigar sobre el papel de la comunicación en situaciones de crisis, y la renovación constante y adaptación a las nuevas exigencias derivadas de la situación económica y del distanciamiento físico (que no social).

\section{MARCO TEÓRICO}

\subsection{Papel de los medios de comunicación}

La indiscutible función de los medios de informar verazmente, paralela al derecho de todos a la información, podría verse matizada en casos de pandemia por razones de salud y estabilidad social. Tanto políticos como sanitarios podrían confundir la función social de los medios con la necesidad de tranquilizar a la población, recurriendo a la ocultación de ciertos hechos. Nos recuerdan Crespo y Garrido (2020), sin embargo, que, en comunicación de crisis, aunque puede resultar una tentación para los gobernantes minimizar el alcance o la gravedad de la situación con el propósito de no

Revista de Comunicación y Salud, 2020, Vol. 10, oㅡ 2, pp. 355-384 
La COVID-19 en la prensa española. Encuadres de alarma y tranquilidad en las portadas de El País, El Mundo y La Vanguardia

causar alarma o pánico entre la población, suele ser siempre una estrategia equivocada. Los medios, por su parte, en consonancia con los políticos, pueden presentar los hechos con encuadres que favorezcan la alarma o la tranquilidad, y no solo por razones de salud pública, como veremos, sino por razones políticas e incluso en contra de la salud pública.

El importante papel de los medios de comunicación convencionales en campañas de salud y en la crisis de la Covid-19 está suficientemente demostrado (Feo-Acevedo y Feo-Istúriz, 2013; Brown, 2020). También los medios digitales son considerados de gran utilidad: La Comisión Europea, en su recomendación adoptaba el 8 de abril de 2020, plantea la conveniencia de utilizar las redes sociales como canales de comunicación complementarios a medios tradicionales como la televisión y la prensa, los dos medios informativos de referencia en otras crisis sanitarias (en Costa-Sánchez y López-García, 2020). El 66,84\% del total de noticias sobre la Covid-19 aparecidas en España (indexadas en la base de datos $M y$ news) se han publicado en medios digitales (Lázaro-Rodríguez y Herrera-Viedma, 2020).

No cabe ninguna duda de la importancia actual de los entornos digitales como escenarios para la labor periodística y la representación de temas de salud pública (Cano-Orón et al, 2020). Los principales medios de comunicación tradicionales cuentan con sus distintas páginas en Internet, y en España contamos con prestigiosos medios nativos digitales, pero la urgencia requerida en la red y la tendencia a responder a las exigencias de inmediatez y de generación de tráfico, pueden poner en peligro la confirmación de veracidad de la noticia y el cumplimiento del protocolo de calidad (Lotero-Echeverri, et al., 2018). Son numerosos los autores que advierten no solo de la información incorrecta (misinformation) sobre la Covid-19, por descuido o incompetencia, sino también de la desinformación con intención de engañar (desinformation) en los medios nativos digitales y en las redes sociales (O'Connor y Murphy, 2020; Pennycook et al., 2020; Tasnim, Hossain y Mazumder,2020; Montesi, 2020).

La infodemia, o situación de miedo e inseguridad generada por la sobreexposición a noticias (sean falsas o verdaderas), en la crisis del coronavirus (Giménez et al., 2020; Cinelli et al. 2020; Hu et al., 2020) constituye terreno abonado para la desinformación y la propaganda política a nivel internacional (Sukhankin, 2020; Gradoń, 2020; Kosmehl, 2020) y nacional (Mayor-Ortega, 2020; Branco, 2020; Euronews, 2020).

El papel de los medios de comunicación españoles ante la pandemia del Covid-19 fue discutido en la reunión virtual de Dircom (Asociación de directivos de comunicación) convocada por Nacho Cardero, director de El Confidencial (Dircom, 2020). Allí se puso de manifiesto que la saturación informativa y la proliferación de bulos y fake news que dificultan su función de distribuir de una información rigurosa y veraz, considerada de primera necesidad. Cardero admitió, sin embargo, que en España, aunque en un primer momento hubo una especie de cordialidad a la hora de cubrir la información, en la que los medios se centraban en la crisis sanitaria, según pasaban los días, se volvían algo 
La COVID-19 en la prensa española. Encuadres de alarma y tranquilidad en las portadas de El País, El Mundo y La Vanguardia

indolentes y pasaban el foco de atención a la crisis económica, centrándose en los miles de parados, para pasar más tarde a priorizar la cobertura sobre la crisis política.

Una tendencia similar se ha comprobado en nuestro estudio centrado en tres medios impresos nacionales: El país, El mundo y La vanguardia. En él se comparan las portadas de los tres periódicos durante marzo y abril de 2020 para analizar cómo cada uno enfoca la crisis de la Covd-19; si se transmite sensación de alerta o de tranquilidad injustificada, y a qué razones puede deberse el posible sesgo en el encuadre.

\subsection{Los marcos de interpretación (framing) en la cobertura de la crisis}

La teoría del framing o teoría del encuadre o de los marcos está, según McCombs, Shaw, and Weaver, directamente relacionada con la teoría de la fijación de la agenda, y podría considerarse como una extensión de esta (en Scheufele, 1999). El framing o encuadre puede definirse como un proceso en el que se seleccionan algunos aspectos de la realidad, a los que les otorgará un mayor énfasis o importancia, de manera que se define el problema, se diagnostican sus causas, se sugieren juicios morales y se proponen soluciones y conductas apropiadas a seguir (Entman, 1993). Este proceso de encuadre se lleva a cabo con una cuidadosa selección del vocabulario y la sintaxis que se utilizan en las discusiones, 0 con la presentación de contextos (visual o informacional) que provocarán determinadas interpretaciones por parte de la audiencia. (Dobson y Knezevic, 2018). En el caso de la prensa, esta cuidadosa selección de texto e imágenes es aún más evidente en las portadas, de ahí nuestra elección para este estudio.

Según Ardèvol-Abreu (2015) el desarrollo de la investigación sobre framing en España ha experimentado una rápida evolución desde mediados de los años sesenta hasta la actualidad. El framing no solo sitúa el análisis en los emisores de información, sino que el encuadre está localizado en cuatro elementos del proceso de comunicación: el emisor, el receptor, el texto (informativo) y la cultura. En esta misma línea, Muñiz Muriel afirma que cuando estamos trabajando con la Teoría de la Agenda, ésta nos dice por qué se seleccionan ciertos temas o no, cuando estamos trabajando con la Teoría del Framing lo que nos dice es por qué trasladamos hacia la ciudadanía y la opinión pública una visión y no otra de ese tema, por qué enfatizamos un punto de vista y no otro, por qué planteamos como principal un enfoque y no otro, por qué enfatizamos un encuadre y no otro. Coincidimos con Muñiz Muriel en que el framing no se queda en el proceso de producción de la noticia, sino que nos permite profundizar mucho más en la comprensión del contenido que se está trasladando hacia la ciudadanía y nos permite detectar el impacto real que eso está teniendo (Muñiz-Muriel, 2014).

La Teoría del Encuadre o framing, que nace en el contexto de la psicología y de la sociología interpretativa (Sádaba, 2001), se aplica predominante en los estudios de comunicación a la función informativa de los medios, y más en concreto a la información política y electoral. Carter (2013) analiza la investigación llevada a cabo sobre frames and framing y nos ofrece ejemplos de tres áreas donde la utilización del framing es más habitual: en política, en deportes y en epidemias. En los casos de

Revista de Comunicación y Salud, 2020, Vol. 10, nº 2, pp. 355-384 
La COVID-19 en la prensa española. Encuadres de alarma y tranquilidad en las portadas de El País, El Mundo y La Vanguardia

pandemia, como el que aquí nos ocupa, al sesgo sensacionalista de la prensa amarilla y medios sociales se une el sesgo inducido por la emoción en la audiencia. Según DeStefano (2020), el miedo hace que nos volvamos más susceptibles de creer declaraciones falsas y adoptar actitudes potencialmente problemáticas, hostiles 0 temerosas hacia quienes nos rodean, declaraciones y actitudes que a su vez refuerzan nuestro miedo e incrementan el ciclo.

Lerner et al. (2003) ya demostraron cómo el miedo y el odio cambian nuestras creencias y actitudes sobre asuntos de interés nacional, algo que parece se ha tenido últimamente bien en cuenta en campañas políticas como las del Brexit y la elección de Trump (Gabbatt, 2016; Norris y Inglehart, 2019).

En las crisis de salud pública no es tan fácil distinguir la línea que separa el informar del atemorizar, no es tan fácil saber cuándo la noticia ayuda, daña o alarma (Chechik, 2020). Los profesionales se plantean cómo trasmitir información relevante sin caer en el sensacionalismo ni provocar pánico, y cómo combinar los encuadres que trasmiten la seriedad de la situación con los que pretenden atraer la atención (Civeris et al, 2020).

El tratamiento informativo de la Covid-17 en los medios sensacionalistas ha dado lugar a una epidemia de bulos y rumores alarmistas que alimentan exponencialmente la pandemia de desinformación en la era de la postverdad, las fake news, los deep fake y las "verdades alternativas", hasta el punto de llevar al secretario general de la ONU, António Guterres, al presentar recientemente la iniciativa Verified, a manifestar: "No podemos ceder nuestros espacios virtuales a quienes trafican con mentiras, miedo y odio" (Noticias ONU, 2020).

En torno al coronavirus, Ariel- Giménez et al. (2020) han identificado tres tipos de noticias falsas: aquellas relacionadas con la salud y supuestos consejos para prevenir 0 curar la enfermedad (la mayoría); las políticas, referidas a supuestas medidas del Gobierno o de acciones específicas de un dirigente; y aquellas que tienen que ver con supuestas decisiones administrativas que afectan vida cotidiana de la población. Recordemos que la desinformación no necesariamente obedece a la intención de alguien de engañar a la audiencia, sino que también puede ser involuntaria, dependiente de los valores, creencias y el marco conceptual desde el que los emisores miran y encuadran al mundo (Nogués, 2018).

Vivimos, según Amorós (2020, p. 20), "inmersos en el fuego cruzado de una guerra de noticias falsas que batallan por imponer una visión del mundo mientras, desde el periodismo y el pensamiento, intentamos luchar contra ellas". Las noticias -según el autor- han dejado de ser un instrumento para la difusión de conocimiento y la construcción de un relato acorde a los hechos y no a las opiniones. Predominan las noticias que contribuyen a "la construcción de narrativas emocionales que enmarquen la realidad conforme a una ideología y a unos prejuicios" (ibídem).

También otros autores, como Qin (2015), observan importantes diferencias entre la forma de encuadrar un acontecimiento en las medios tradicionales, con más control por

Revista de Comunicación y Salud, 2020, Vol. 10, nº 2, pp. 355-384 
profesionales, y la forma en que lo hacen los medios sociales, mientras que otros como Elías (2018), por ejemplo, ante la victoria de Trump a pesar de su "mala prensa", se preguntan si los medios tradicionales, que en su mayoría se manifestaron en contra del candidato, no habrán perdido poder frente a las redes.

Dobson y Knezevic (2018) mantienen que unos y otros se retroalimentan, refuerzan $y$, por lo tanto, se reproduce el mismo discurso, incluidos los estereotipos. En cualquier caso, la interrelación e influencia mutua es incuestionable. Es fácil comprobar cómo cualquier trending topic o noticia que triunfe en las redes sociales suele recogerse también en los medios de comunicación. En este sentido se podría afirmar que el impacto de las redes sociales en la población condiciona los temas y la agenda de los medios, pero también hay que tener en cuenta que gran parte de la información que se recoge y difunde en las redes sociales se toma de los medios de comunicación.

En pocas ocasiones resulta más evidente la responsabilidad social tanto de medios como de redes sociales que en la cobertura informativa de las crisis, desastres y emergencias, ya que en momentos de confusión e infoxicación el público puede otorgar idéntica credibilidad a los bulos que a las fuentes oficiales (Mayo-Cubero, 2020). Corresponde a los medios más prestigiosos no solo mantener su credibilidad sino contrarrestar la influencia negativa de las noticias falsas con una información de servicio público basada en hechos contrastados y encuadres lo más objetivos posible. Desde el inicio de esta crisis sanitaria, las noticias se han convertido en un valioso recurso para la ciudadanía y los medios tradicionales han recobrado protagonismo. Según CaseroRipollés (2020) las agencias gubernamentales y las noticias de los medios inspiran más confianza en la audiencia que la información de las redes sociales, donde no suelen encontrase científicos entre los influencers.

Tampoco se puede caer en el error de asociar los bulos a las redes sociales, y dar por supuesto que la información más veraz se encuentra en las fuentes oficiales y en los medios de comunicación. Hao y Basu (2020) advierten que, aunque los medios sociales contribuyan a la desinformación, también han sido una fuente importante de información verificada sobre la Covid-19. Las redes sociales en China, con sus anécdotas e informes, han servido a periodistas de todo El mundo para tener una visión más acertada de lo que está ocurriendo en ese país, al tiempo que sirven también para forzar al propio Gobierno a mejorar la información. Papel similar juegan las redes en el caso de Hungría, donde el Gobierno, en un nuevo intento de acabar con la libertad de expresión, se ha escusado en el coronavirus para suprimir los medios independientes y convertir los oficialistas en un instrumento de propaganda a su favor (Urbán, 2020). En Venezuela, según Canelón-Silva (2020) el Gobierno ha creado una narrativa favorable en los medios oficialistas que influye en la percepción de los hechos apelando a las emociones de la audiencia.

\section{OBJETIVOS}

La comunicación en tiempos de pandemia se ha convertido en un tema de gran actualidad y nos parece pertinente destacar la consideración de los medios no solo 
La COVID-19 en la prensa española. Encuadres de alarma y tranquilidad en las portadas de El País, El Mundo y La Vanguardia

como servicio público sino también, y en el mismo sentido, como importantes agentes de educación. Apuntamos la función socializadora y pedagógica de los medios de comunicación que guían a los públicos sobre cómo proceder en una circunstancia tan excepcional como es la de pandemia.

En el estudio se parte del supuesto de que los medios no solo determinan la agenda de temas de interés y debate público, sino que también definen una serie de marcos o pautas que inclinan a las audiencias a determinadas interpretaciones de los contenidos que presentan, y les invitan, incluso, a una toma de postura y actitud personal. Se parte, por lo tanto, del potencial de los medios de comunicación para crear estados de opinión, posturas ideológicas e incluso para influir en el comportamiento cívico de las audiencias. Se comparan las portadas de El país, El mundo y La vanguardia durante los meses de marzo y abril de 2020 para detectar posibles encuadres que intenten generar alerta o tranquilidad, y si las motivaciones podrían ser fundamentalmente políticas.

La relevancia del trabajo se justifica por el detallado análisis de la cobertura periodística y la selección de la información prioritaria (de portada). Se detecta la presencia de mensajes de alarma o de calma no correspondientes al hecho noticioso, y se comparan los distintos frames periodísticos empleados a lo largo de los dos primeros meses del estado de alarma en España por la enfermedad Covid-19.

El principal objetivo del estudio es analizar si los citados medios han trasladado los hechos noticiosos a través de mensajes de alarma o de tranquilidad injustificados y si ese enfoque favorece o perjudica a los agentes políticos responsables.

\section{METODOLOGÍA}

Para averiguar si en las noticias incluidas en portada por los tres medios más leídos en España (El país, El mundo y La vanguardia) en los meses de marzo y abril de 2020 se han transmitido mensajes de alarma o de tranquilidad por sensacionalismo o con fines políticos, se analizan los encuadres adoptados por los tres periódicos en sus portadas, con el propósito de:

- Detectar el predominio del sensacionalismo sobre la función informativa y objetiva identificando el carácter evaluativo de cada una de las noticias analizadas.

- Comprobar si los enfoques de alarma o tranquilidad han sido aplicados por todos los medios ante las mismas noticias. Saber si existe una relación entre el discurso de alarma o de tranquilidad y la defensa o el ataque explícitos a las instituciones y políticos responsables de la gestión de la crisis.

La elección de la muestra viene determinada por el último informe de 2019 de la AIMC (2019) correspondiente a la $3^{\text {a }}$ ola y cuyos resultados coinciden con los de la $1^{\text {a }}$ ola de 2020. En ellos, el Estudio General de Medios (EGM) sitúa a El país como el diario no deportivo más leído, seguido de El mundo y de La vanguardia en tercer lugar. Teniendo en cuenta que las ediciones digitales de los diarios se actualizan a lo largo del día, se ha elegido la portada de los diarios en su versión impresa. Como en otras muchas investigaciones (Kim y Chung, 2017; Niemeyer, 2019; Slakoffy Brennan, 2019)

Revista de Comunicación y Salud, 2020, Vol. 10, nº 2, pp. 355-384 
La COVID-19 en la prensa española. Encuadres de alarma y tranquilidad en las portadas de El País, El Mundo y La Vanguardia

se han considerado las portadas de los periódicos como suficientemente significativas y fuente válida para alcanzar los objetivos de esta investigación.

En total, se han revisado 1.154 noticias de portada e identificado para el análisis 405 elementos pertenecientes a 162 hechos noticiosos comunes, que conforman la muestra de este estudio (125 noticias de El país, 133 de El mundo y de 115 La vanguardia). Se han encontrado otras 42 noticias comunes pertenecientes a asuntos como obituarios y efemérides no vinculadas a la actualidad política ni a la crisis de la Covid-19, que se han descartado por su falta de relevancia.

Se consideran las fotografías de portada de gran relevancia en la construcción del relato informativo, y objeto de un análisis específico, por lo que no se han incluido en este estudio como elementos de análisis. No obstante, sí se ha procesado la carga emotiva de las imágenes pertenecientes a noticias de la muestra.

Para elaborar el instrumento de análisis se ha partido de herramientas de medición de framing ya validadas y empleadas en numerosos artículos de referencia (Semetko y Valdenburg, 2000; Igartua et al, 2005a y 2005b; Igartua, 2007; Ardèvol-Abreu, 2015 y 2016). Siguiendo el modelo de inmersión cualitativa propuesto por Igartua et al, (2005b), para la elaboración de su escala ENI (Encuadres Noticiosos de la Inmigración), se creó la ficha de registro que permitiera recoger palabras y expresiones clave de las noticias de la muestra. Se han tenido además en cuenta las aportaciones de NogueraVivo (2006) sobre el análisis del framing en la información de la catástrofe, así como las consideraciones de Carter (2013) sobre la construcción de la realidad.

El instrumento de análisis o ficha de registro resultante consta de 23 variables que se organizan en 7 bloques (Tabla 1).

Tabla 1: Ficha de registro.

\begin{tabular}{|c|c|}
\hline Área de análisis & Variables correspondientes \\
\hline $\begin{array}{l}\text { Bloque 1: } \\
\text { Elementos } \\
\text { técnicos. }\end{array}$ & $\begin{array}{ll}\text { 1. } & \text { Fecha. } \\
\text { 2. } & \text { Medio. } \\
\text { 3. } & \text { Noticia. } \\
\text { 4. } & \text { Área temática. } \\
\end{array}$ \\
\hline $\begin{array}{l}\text { Bloque } 2 \text { : } \\
\text { Posicionamiento } \\
\text { y relevancia. }\end{array}$ & $\begin{array}{l}\text { 5. Tamaño de la fuente } \\
\text { 6. Tercio de la portada en que está ubicada la noticia } \\
\text { 7. Cuarto/ espacio que ocupa la noticia }\end{array}$ \\
\hline $\begin{array}{l}\text { Bloque } 3 . \\
\text { Elementos } \\
\text { subjetivos }\end{array}$ & $\begin{array}{l}\text { 8. Identificación cualitativa del enfoque temático del hecho noticioso. } \\
\text { 9. Carácter evaluativo. } \\
\text { 10. ¿Se desprende del relato de la noticia un carácter } \\
\text { sensacionalista? } \\
\text { 11. Elemento emotivo destacado ¿cuál es? } \\
\text { 12. ¿Se usa en la noticia algún término vinculado a lenguaje bélico } \\
\text { literal? }\end{array}$ \\
\hline $\begin{array}{l}\text { Bloque } 4 . \\
\text { Enfoque } \\
\text { alarmista. }\end{array}$ & $\begin{array}{l}\text { 13. El mensaje transmite dolor o tristeza. } \\
\text { 14. El mensaje transmite miedo o alarma. } \\
\text { 15. El mensaje transmite un peligro inminente y de gran magnitud. }\end{array}$ \\
\hline
\end{tabular}

Revista de Comunicación y Salud, 2020, Vol. 10, № 2, pp. 355-384 
La COVID-19 en la prensa española. Encuadres de alarma y tranquilidad en las portadas de El País, El Mundo y La Vanguardia

\begin{tabular}{|l|l|}
\hline & $\begin{array}{l}16 . \text { El mensaje transmite rabia o enfado. } \\
17 . \quad \text { ¿El relato sugiere que el problema requiere acción urgente? }\end{array}$ \\
\hline $\begin{array}{l}\text { Bloque 5. } \\
\text { Enfoque } \\
\text { tranquilizador. }\end{array}$ & $\begin{array}{l}\text { 18. El mensaje transmite calma, positividad o alegría. } \\
\text { 19. El mensaje es tranquilizante u optimista. }\end{array}$ \\
\hline $\begin{array}{l}\text { Bloque 6. } \\
\text { Ataque al } \\
\text { Gobierno. }\end{array}$ & $\begin{array}{l}\text { 20. ¿El relato sugiere que algún nivel del Gobierno es responsable de } \\
\text { la cuestión o el problema? }\end{array}$ \\
\hline $\begin{array}{l}\text { Bloque desprende de la noticia desconfianza en la capacidad de las } \\
\text { Defensa del } \\
\text { Gobierno }\end{array}$ & $\begin{array}{l}\text { instituciones para dar respuestas efectivas al asunto o problema? } \\
\text { ¿Identifica el relato del hecho noticioso a un héroe que resuelve o } \\
\text { manifiesta cómo resolver el conflicto? }\end{array}$ \\
\hline
\end{tabular}

Fuente: Elaboración propia.

Los bloques 1 y 2 se han procesado para extraer información descriptiva sobre la muestra.

El bloque 3 da cuenta del carácter evaluativo de las noticias e indica la tendencia subjetiva del relato. Por una parte, se ha analizado si el carácter evaluativo era de signo positivo, negativo o neutro. Además, se ha computado el marco subjetivo en las noticias con presencia de alguno de los recursos identificados: términos bélicos, elementos emotivos destacados o el carácter sensacionalista que se desprende del relato.

El bloque 4 recoge el alarmismo, bajo este enfoque queda reflejada la presencia de al menos dos de los cuatro indicadores: dolor/tristeza, miedo/alarma, peligro inminente, rabia/ enfado o se requiere acción urgente. El bloque 5 refleja el enfoque tranquilizador de las noticias, constata la presencia de uno de los dos indicadores, la trasmisión de calma, positividad o alegría y si el mensaje es tranquilizante.

Finalmente, en los dos últimos bloques, 6 y 7 , se ha reflejado el perjuicio que supone el enfoque de la noticia para el Gobierno y su defensa, con la constatación de uno de los dos indicadores registrados en cada caso.

El análisis contrasta la presencia de los cuatro enfoques en el discurso comparando en los tres diarios seleccionados mediante el estadístico Chi-cuadrado. Además, se pone a prueba la ocurrencia simultánea de varios enfoques obtenida a través del coeficiente de Contingencia. Se trata de averiguar si los enfoques de alarma y de tranquilidad están asociados a los de ataque y defensa a las instituciones y políticos responsables.

Para completar el estudio, y a través de una evaluación cualitativa de los hechos identificados como alarmistas u optimistas de forma unánime o diferenciada, se ha tratado de averiguar la justificación de dichos enfoques. 
Previo al análisis de resultados se clasifican las noticias en función del área temática al que pertenecen: Avance del coronavirus en España (84 noticias), gestión del Gobierno (149), medidas y repercusiones económicas de la crisis sanitaria (65), medidas y repercusiones educativas de la crisis sanitaria (11), conflictos en el seno del Ejecutivo o entre este y las autonomías (30) y conflicto catalán (10). Asimismo, se han identificado otras noticias clasificadas como internacionales (34) que se han seleccionado para valorar si el carácter evaluativo de las noticias de la crisis está presente cuando el hecho noticioso se ubica fuera de nuestras fronteras. La comparación de las noticias por diarios muestra que la cobertura de cada tema ha sido tratada con la misma frecuencia en los tres diarios analizados (Chi-cuadrado $=3,415$; g.l. $=14$; sig=0,998), en coherencia con el procedimiento de selección basado en los hechos noticiosos comunes.

Tabla 2. Clasificación temática de las noticias por diario

\begin{tabular}{|l|c|c|c|c|}
\hline \multicolumn{1}{|c|}{ Temática de las noticias } & El país & El mundo & La vanguardia & Total \\
\hline Avance del virus & $19,7 \%$ & $21,4 \%$ & $19,1 \%$ & $20,1 \%$ \\
\hline Gestión del Gobierno & $35,2 \%$ & $36,6 \%$ & $35,1 \%$ & $35,6 \%$ \\
\hline Noticias económicas & $16,2 \%$ & $13,1 \%$ & $17,6 \%$ & $15,6 \%$ \\
\hline Conflictos del Ejecutivo & $5,6 \%$ & $7,6 \%$ & $8,4 \%$ & $7,2 \%$ \\
\hline Noticias internacionales & $9,2 \%$ & $7,6 \%$ & $7,6 \%$ & $8,1 \%$ \\
\hline Medidas y repercusiones educativas & $3,5 \%$ & $2,8 \%$ & $1,5 \%$ & $2,6 \%$ \\
\hline Conflicto Catalán & $2,1 \%$ & $2,8 \%$ & $2,3 \%$ & $2,4 \%$ \\
\hline Otros & 8,5 & $8,3 \%$ & $8,4 \%$ & $8,4 \%$ \\
\hline Chi-cuadrado = 3,415; g.l.=14 sig. =,998
\end{tabular}

Fuente: Elaboración propia.

\section{RESULTADOS}

\subsection{El carácter evaluativo de las noticias}

La primera aproximación sobre la objetividad en el tratamiento de la información se lleva a cabo mediante el análisis sobre el carácter evaluativo de las noticias. Según se muestra en la tabla 3, la neutralidad está presente en la mitad de las noticias analizadas $(50,5 \%)$, en el $36 \%$ de los casos la valoración toma un cariz negativo y el $13,4 \%$ restante positivo. A la hora de descifrar los ámbitos temáticos en los que se produce más neutralidad en su tratamiento encontramos las noticias internacionales, como cabría esperarse, con un 70,6\% ubicado en la imparcialidad. En este mismo sentido, destacan las noticias sobre la gestión del Gobierno, en la que se produce mayor neutralidad de lo que obtiene el conjunto de la muestra. En el apartado negativo destacan con mayor proporción las noticias económicas, y en el positivo las noticias sobre el avance del virus. 
La COVID-19 en la prensa española. Encuadres de alarma y tranquilidad en las portadas de El País, El Mundo y La Vanguardia

Tabla 3. Carácter evaluativo de las noticias por tema

\begin{tabular}{|l|c|c|c|c|}
\hline Temática de las noticias & Negativo & Positivo & Neutro & $\mathrm{N}$ \\
\hline Avance del virus & $36,9 \%$ & $23,8 \%$ a & $39,3 \%$ b & 84 \\
\hline Gestión del Gobierno & $31,5 \%$ & $10,1 \%$ & $58,4 \%$ a & 149 \\
\hline Noticias económicas & $49,2 \%$ a & $13,8 \%$ & $36,9 \%$ & 65 \\
\hline Conflictos del Ejecutivo & $43,3 \%$ & $10,0 \%$ & $46,7 \%$ & 30 \\
\hline Noticias internacionales & $26,5 \%$ & $2,9 \%$ b & $70,6 \%$ a & 34 \\
\hline Medidas y repercusiones educativas & $45,5 \%$ & $0 \%$ & $54,5 \%$ & 11 \\
\hline Conflicto Catalán & $50,0 \%$ & $0 \%$ & $50 \%$ & 10 \\
\hline Otros & $25,7 \%$ & $22,9 \%$ & $51,4 \%$ & 35 \\
\hline Total & $36,1 \%$ & $13,4 \%$ & $50,5 \%$ & 418 \\
\hline $\begin{array}{l}\text { Chi-cuadrado = 32,504; g.l.=14 sig. =,003 } \\
\text { Coeficiente de Contingencia = ,269 sig. }=, 003\end{array}$ \\
\hline
\end{tabular}

Fuente: Elaboración propia.

A continuación, se pone a prueba si todos los diarios han mantenido el mismo margen de imparcialidad en el tratamiento informativo. Para ello se compara el carácter evaluativo del conjunto de noticias en los tres diarios. Según se aprecia en la tabla 4, la postura mantenida por los tres diarios analizados difiere entre sí, siendo las diferencias estadísticamente significativas (Chi-cuadrado $=52,660 ;$ g.l. $=4$ sig. $=, 000$ ). El diario El país mantiene en mayor proporción una valoración positiva de los acontecimientos que en los otros dos diarios, al mismo tiempo que muestra en menor medida la cara negativa de las noticias. Por su parte, el diario El mundo mantiene de forma clara una mayor visión negativa de los contenidos abordados en sus portadas, en detrimento de las noticias con un enfoque neutral. La vanguardia mantiene en mayor proporción la postura neutral y menor presencia de los enfoques negativos, al igual que el diario El país.

Tabla 4. Carácter evaluativo de las noticias por diario

\begin{tabular}{|c|c|c|c|c|}
\hline Carácter evaluativo & El país & El mundo & La vanguardia & Total \\
\hline Positivo & $23,1 \%$ a & $6,9 \%$ & $9,9 \%$ b & $13,4 \%$ \\
\hline Negativo & $25,2 \% b$ & $55,6 \%$ a & $25,2 \%$ & $36,0 \%$ \\
\hline Neutro & $51,7 \%$ & $36,6 \% b$ & $64,9 \%$ a & $50,6 \%$ \\
\hline $\mathrm{N}$ & 143 & 145 & 131 & \\
\hline \multicolumn{5}{|c|}{$\begin{array}{l}\text { Chi-cuadrado = 52,660; g.I }=4 \text { sig. }=, 000 \\
\text { Coeficiente de Contingencia =0,334 (sig. }=, 000)\end{array}$} \\
\hline \multicolumn{5}{|c|}{$\begin{array}{l}\text { a indica que el porcentaje de la casilla es significativamente superior al esperado a } \\
\text { un nivel de confianza } p<, 05 \text {. } \\
\text { b indica que el porcentaje de la casilla es significativamente superior al esperado a } \\
\text { un nivel de confianza } p<, 05\end{array}$} \\
\hline
\end{tabular}

Fuente: Elaboración propia. 
La COVID-19 en la prensa española. Encuadres de alarma y tranquilidad en las portadas de El País, El Mundo y La Vanguardia

\subsection{Enfoques presentes en las noticias}

A continuación, se describen la incidencia de los enfoques utilizados en el análisis de contenido cuyos resultados se muestran en la tabla 5 . Bajo el enfoque subjetivo se registran el $46,5 \%$ de las noticias analizadas. La comparación entre medios evidencia una clara asociación del sensacionalismo en el diario El mundo, seis de cada diez noticias publicadas en este diario contienen al menos dos elementos vinculados a este marco interpretativo. Mientras que el diario de La Vanguardia destaca por hacer un uso significativamente más moderado de este recurso.

Dentro del marco alarmista se encuadran un tercio de las noticias $(29,6 \%)$, en el que, de nuevo, destaca el diario El mundo con mayor incidencia en las llamadas a la emergencia en el tratamiento de la información (42,1\%). De nuevo, el diario La vanguardia recurre con menor frecuencia a este encuadre amenazante.

El tono tranquilizador de los mensajes se constata en el 15,5\% de las noticias, siendo El país el diario que en mayor medida recurre a las llamadas a la calma $(26,6 \%)$, frente al El mundo, que adopta con menos frecuencia estas claves positivas en los mensajes.

La atribución de la responsabilidad al Gobierno se evidencia en el $21,7 \%$ de las noticias. En este enfoque destaca de forma significativa El mundo con una frecuencia del $37,9 \%$, mientras que, tanto El país como La vanguardia, rebajan de forma notoria este nivel de atribución.

Por último, la defensa del Gobierno se identifica en el $11,5 \%$ de las informaciones analizadas y no se dan diferencias estadísticamente significativas entre los tres diarios, aunque se aprecia una tendencia en El país a abordar con más frecuencia esta postura defensiva hacia la gestión del Ejecutivo.

Tabla 5. Enfoques de las noticias por diario

\begin{tabular}{|c|c|c|c|c|c|}
\hline & El país & El mundo & La vanguardia & Total & $\begin{array}{c}\text { Chi- } \\
\text { cuadrado }\end{array}$ \\
\hline Enfoque subjetivo & $41,3 \%$ b & $60,7 \%$ a & $36,6 \%$ & $46,5 \%$ & $\begin{array}{c}18,430 \\
(, 000)\end{array}$ \\
\hline Enfoque alarmista & $24,5 \%$ & $42,1 \%$ a & $21,4 \%$ b & $29,6 \%$ & $\begin{array}{l}16,876 \\
(, 000)\end{array}$ \\
\hline Enfoque tranquilizador & $26,6 \%$ a & $6,2 \%$ & $13,7 \%$ & $15,5 \%$ & $\begin{array}{l}17,969 \\
(, 000)\end{array}$ \\
\hline Ataque al Gobierno & $11,9 \%$ b & $37,9 \%$ a & $14,5 \%$ b & $21,7 \%$ & $\begin{array}{c}34,556 \\
(, 000)\end{array}$ \\
\hline Defensa del Gobierno & $16,1 \%$ & $11,0 \%$ & $6,9 \%$ & $11,5 \%$ & $5,761(, 056)$ \\
\hline \multicolumn{6}{|c|}{$\begin{array}{l}\text { a indica que el porcentaje de la casilla es significativamente superior al esperado a un nivel } \\
\text { de confianza } p<, 05 \text {. } \\
\text { b indica que el porcentaje de la casilla es significativamente superior al esperado a un nivel } \\
\text { de confianza } p<, 05\end{array}$} \\
\hline
\end{tabular}

Fuente: Elaboración propia. 
Se ha comprobado que el enfoque alarmista aparece con más frecuencia vinculado a las noticias económicas, el $56,9 \%$ de las noticias económicas evocan mensajes asociados al miedo, esta relación es estadísticamente significativa (Chi-cuadrado = 44,145; g.l.=7 sig. =,000). En contraste, el enfoque tranquilizador está más asociado a las noticias sobre el avance del virus; aunque esta relación no alcanza la significación estadística, se constata esta tendencia, como se puede apreciar en la tabla 6.

Tabla 6. Temática de las noticias bajos los enfoques alarmista y tranquilizador

\begin{tabular}{|l|c|c|}
\hline Temática de las noticias & $\begin{array}{c}\text { Enfoque } \\
\text { alarmista }\end{array}$ & $\begin{array}{c}\text { Enfoque } \\
\text { tranquilizador }\end{array}$ \\
\hline Avance del virus & $31,0 \%$ & $23,8 \%$ a \\
\hline Gestión del Gobierno & $28,9 \%$ & $16,8 \%$ \\
\hline Noticias económicas & $56,9 \%$ a & $16,9 \%$ \\
\hline Conflictos del Ejecutivo & $33,3 \%$ & $10,0 \%$ \\
\hline Noticias internacionales & $2,9 \%$ & $2,9 \%$ b \\
\hline Medidas y repercusiones educativas & $0,0 \%$ & $0 \%$ \\
\hline Conflicto Catalán & $20,0 \%$ & $0 \%$ \\
\hline Otros & $14,3 \%$ & $11,4 \%$ \\
\hline Total & $29,6 \%$ & $15,5 \%$ \\
\hline Chi-cuadrado (sig.) /gl =7 & $44,145(, 000)$ & $13,925(, 053)$ \\
\hline Coeficiente de Contingencia (sig.) &, $309(, 000)$ &, $180(, 053)$ \\
\hline $\begin{array}{l}\text { a indica que el porcentaje de la casilla es significativamente superior al esperado a } \\
\text { un nivel de confianza p<,05. } \\
\text { b indica que el porcentaje de la casilla es significativamente superior al esperado a } \\
\text { un nivel de confianza p<,05 }\end{array}$ \\
\hline
\end{tabular}

Fuente: Elaboración propia.

Para examinar si los mensajes se construyen en un tono alarmante o tranquilizador con la intención de perjudicar o favorecer al Gobierno se ha llevado a cabo un análisis de contingencia poniendo a prueba la concurrencia simultánea de ambos enfoques. Para ello, se identifica cuántas noticias de las clasificadas como alarmistas coinciden en el ataque al Gobierno (bloque 6), y cuántas de las tranquilizadoras reflejan a su vez, una defensa al Gobierno (bloque 7). En este análisis se ha llevado a cabo de forma independiente en cada diario.

Las noticias con enfoque alarmista están asociadas con los ataques al Gobierno de forma significativa en el diario El mundo, y en el $55,7 \%$ de las noticias bajo este enfoque también se hace alguna referencia al Gobierno como responsable. El coeficiente de Contingencia obtenido es 0,298 , indicando una asociación moderada y estadísticamente significativa entre ambos marcos interpretativos. En los otros dos diarios se constata la independencia de la atribución de responsabilidad al ejecutivo y la clave de alarma. Por otra parte, cuando las noticias adoptan el enfoque tranquilizador, también se produce una defensa de las decisiones gubernamentales, esta relación es significativa en los tres diarios. El coeficiente de Contingencia se sitúa en 0,235, para el diario El país, en 0,392 para La vanguardia y en 0,481 para El mundo. 
La COVID-19 en la prensa española. Encuadres de alarma y tranquilidad en las portadas de El País, El Mundo y La Vanguardia

Tabla 7. Relación entre los enfoques de las noticias y su intencionalidad política por medio

\begin{tabular}{|l|c|c|c|c|}
\hline & $\begin{array}{c}\text { El } \\
\text { mundo }\end{array}$ & El país & $\begin{array}{c}\text { La } \\
\text { vanguardia }\end{array}$ & Total \\
\hline Ataque al Gobierno & \multicolumn{4}{|c|}{ Enfoque alarmista \% (n) } \\
\hline No & $44,3 \%(27)$ & $75,0 \%(21)$ & $82,9 \%(29)$ & $\begin{array}{c}78,3 \% \\
(328)\end{array}$ \\
\hline Sí & $55,7 \%(34)$ & $25,0 \%(7)$ & $17,1 \%(6)$ & $21,7 \%(91)$ \\
\hline $\begin{array}{l}\text { Coef. Contingencia } \\
\text { (sig.) }\end{array}$ & $.298(.000)$ & $.154(.075)$ & $.092(.269)$ & \\
\hline Defensa al Gobierno & \multicolumn{4}{|c|}{ Enfoque tranquilizador \%(n) } \\
\hline No & $22,2 \%(2)$ b & $77,8 \%(14)$ b & $57,9 \%(22)$ b & $\begin{array}{c}88,5 \% \\
(371)\end{array}$ \\
\hline Sí & $77,8 \%(7)$ a & $22,2 \%(4)$ a & $42,1 \%(16)$ a & $11,5 \%(48)$ \\
\hline $\begin{array}{l}\text { Coef. } \\
\text { (sig.) }\end{array}$ & $.481(.000)$ & $.235(.006)$ & $.392(.000)$ & \\
\hline $\begin{array}{l}\text { a indica que el porcentaje de la casilla es significativamente superior al esperado a un nivel } \\
\text { de confianza p<,05. } \\
\text { b indica que el porcentaje de la casilla es significativamente superior al esperado a un } \\
\text { nivel de confianza p<,05 }\end{array}$
\end{tabular}

Fuente: Elaboración propia.

\subsection{La veracidad de la alarma y la tranquilidad en noticias con el mismo enfoque}

Se completa el estudio con una evaluación cualitativa de los hechos narrados en las noticias tratadas con alarma o tranquilidad para valorar la necesidad de dicho encuadre. Se observa que algunas de las noticias que los tres medios han tratado con alarmismo recogen hechos negativos y extraordinarios que podrían justificar dicho encuadre, como la situación de los hospitales españoles -especialmente el colapso de las $\mathrm{UCl}$-, la paralización de toda actividad esencial, la pérdida de 900.000 puestos de trabajo en España, la superación de los 10.000 muertos y las numerosas víctimas mortales en residencias de ancianos.

También coinciden en el alarmismo las noticias sobre los contagios entre sanitarios, la situación de trabajadores y empresas, el descenso del PIB o la falta de acuerdo educativo para gestionar la paralización de los centros escolares. En la figura 1, un ejemplo del relato de alarma en los tres medios, destacando (como ya se apuntaba) la contribución de las fotografías a la construcción del mismo. 


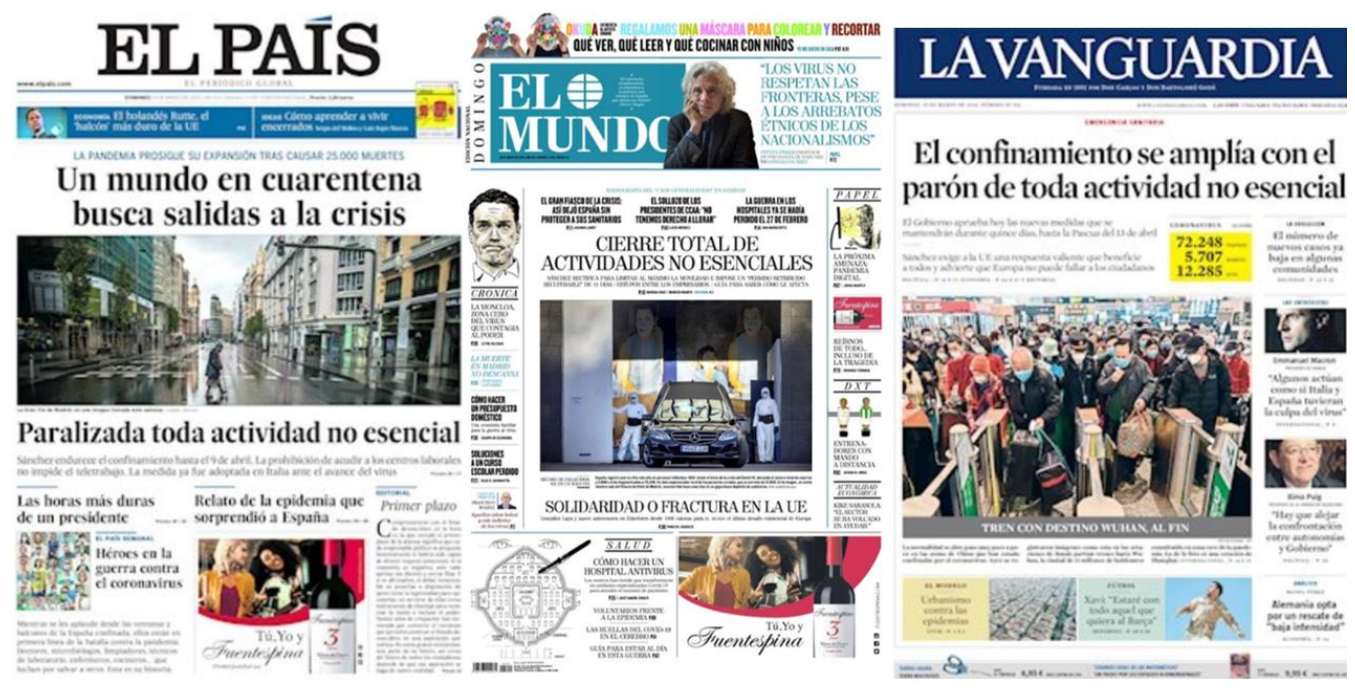

Figura 1. Portadas del 29 de marzo de 2020.

Fuente: El país, El mundo, La vanguardia.

La gravedad podría no estar justificada en noticias sobre los conflictos entre Pedro Sánchez y Pablo Casado, en las críticas de oposición y autonomías al Gobierno o en la actitud independentista de Quim Torra ante la crisis.

Los hechos noticiosos registrados en los tres diarios siempre con enfoque tranquilizador son: la llegada de médicos jubilados y estudiantes para reforzar el sistema sanitario, el anuncio del plan de subsistencia del Gobierno frente al colapso económico, el descenso de las hospitalizaciones, el aumento del número de recuperados y el sucesivo alivio de las $\mathrm{UCl}$, así como el anuncio y la salida de los niños a la calle y la reactivación de la actividad profesional. Todas ellas podrían entenderse como buenas noticias.

En la figura 2 se observa cómo las optimistas cifras de recuperados destacadas por los tres medios quedan eclipsadas por las imágenes de portada escogidas:

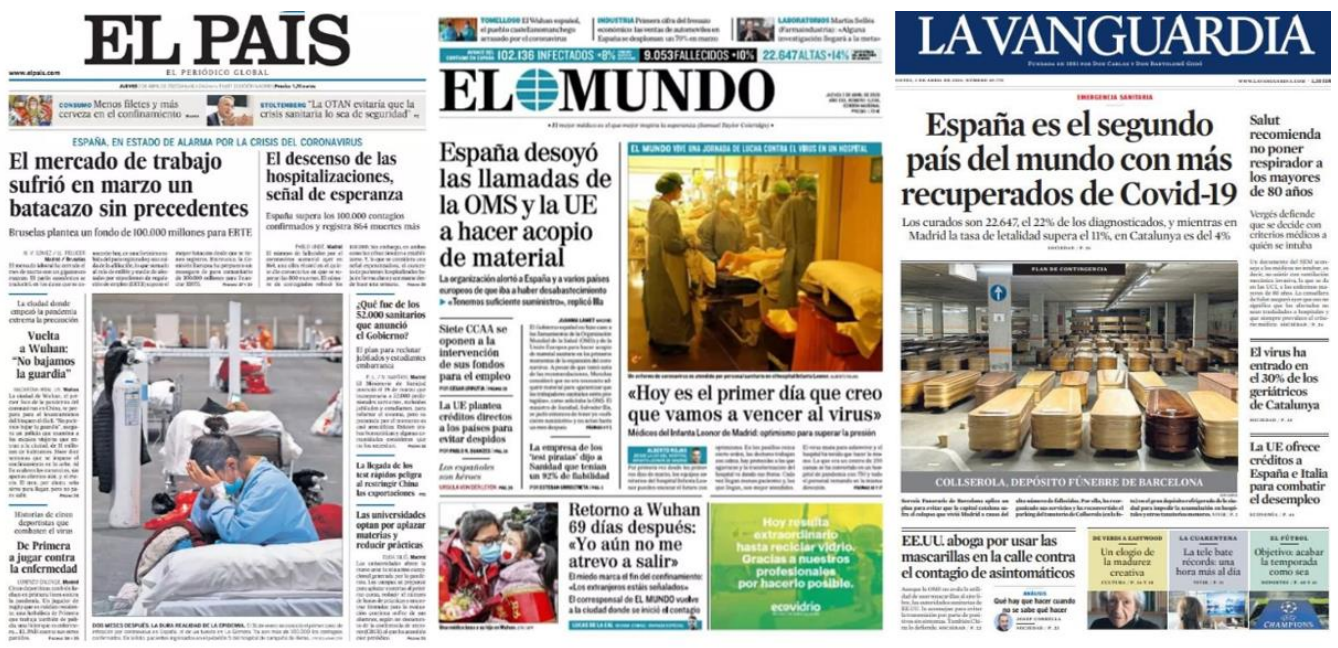

Figura 2. Portadas del 2 de abril 2020.

Fuente: El país, El mundo, La vanguardia. 
La COVID-19 en la prensa española. Encuadres de alarma y tranquilidad en las portadas de El País, El Mundo y La Vanguardia

\subsection{La veracidad de la alarma y la tranquilidad en noticias con distinto enfoque}

La evaluación cualitativa finaliza con una comparación de las noticias en las que al menos un medio presenta un encuadre alarmista o tranquilizador, mientras que otro presenta un enfoque contrario al primero o de carácter neutro.

Como se aprecia en la figura 3 , los problemas de material sanitario se encaran con tranquilidad en El país, diferenciándose de El mundo. Esta tendencia se repite en este medio, que opta por un encuadre de indignación, y en La vanguardia, que aboga por la neutralidad. El país incluye, en general, escasas referencias a la falta de material sanitario. Es destacable que en su portada del 18 de marzo responsabilice a "La sanidad, incapaz de hacer los test necesarios", aludiendo al sector profesional y no al Ministerio de Sanidad, como hace La vanguardia: "Sanidad rectifica y volverá a hacer pruebas a casos leves" y, con mayor insistencia, El mundo.

El país ofrece tranquilidad también al tratar la circunstancia de los trabajadores, contrariamente a La vanguardia (figura 3). Esta polarización no permite justificar ningún enfoque.

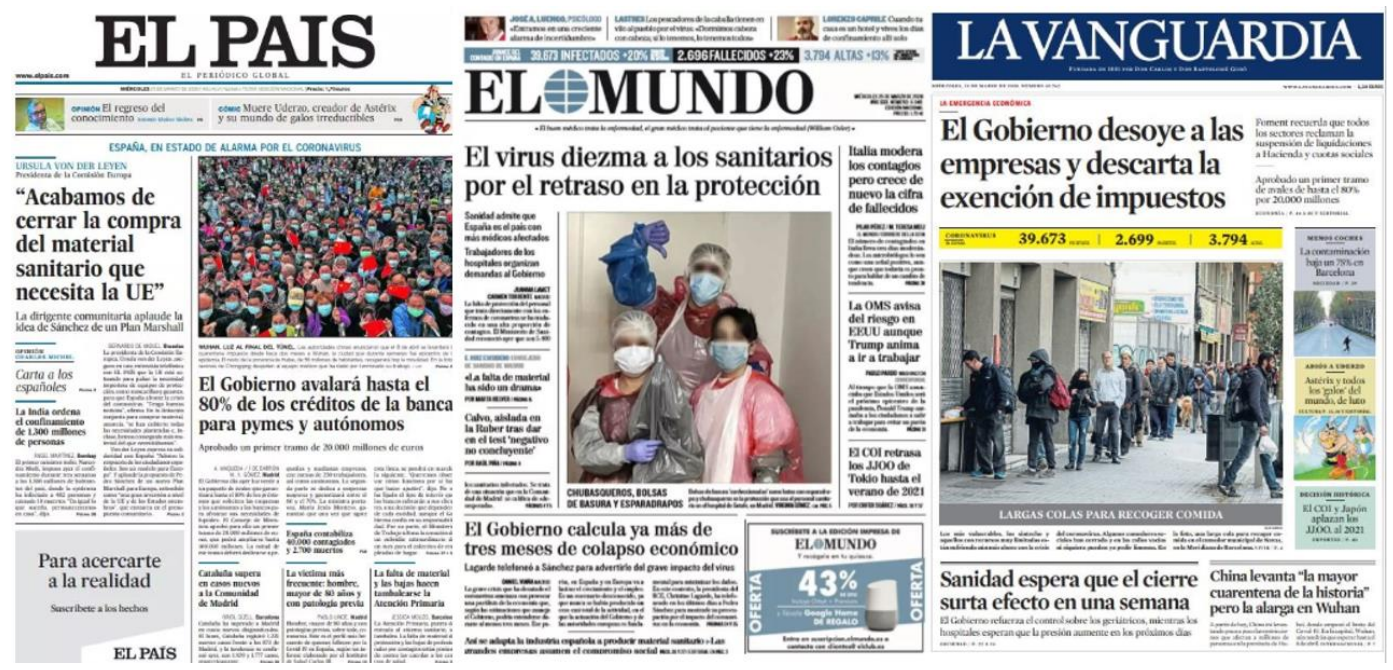

Figura 3. Portadas del 25 de marzo de 2020. Fuente: El país, El mundo, La vanguardia.

El país refleja positivamente el polémico CIS de abril "El $88 \%$ de los encuestados por el CIS pide que se apoye al Gobierno" y El mundo denuncia las preguntas del estudio, con el titular: "El Gobierno utiliza el CIS para justificar la censura a medios". Ninguno de los encuadres es objetivo.

Se aprecia que El país también refleja innecesariamente alarma en otras noticias, como el reparto de enfermos entre autonomías: "Las sanidades autonómicas no se ayudan para aliviar las UCl" frente a la neutralidad que emplea La vanguardia: "Sanidad se plantea el reparto de pacientes entre autonomías". 
La COVID-19 en la prensa española. Encuadres de alarma y tranquilidad en las portadas de El País, El Mundo y La Vanguardia

El mundo revela, como se ha apuntado anteriormente, una tendencia sensacionalista en sus mensajes de alarma que refleja más indignación y enfado que miedo hacia los acontecimientos, como se aprecia en su comunicación del estado de "ALARMA EN DIFERIDO" el 14 de marzo, centrado en la crítica a Pedro Sánchez y en el 8-M, mientras los otros medios recogen la medida.

Si El país enfoca la crisis hospitalaria con escasas referencias al retraso del material de protección: "España supera las 1000 muertes con las UCI de Madrid desbordadas"; El mundo insiste en responsabilizar al Gobierno, situándose en la alerta y, de nuevo, en la indignación: "Las UCl colapsan pero Sanidad todavía no garantizan el material", o "Hacienda auxilia a las CCAA ante el caos logístico de Sanidad". Días más tarde, adoptará la misma tendencia con la imposición de mascarillas en la llamada "deshibernación económica".

La evolución del virus se traslada objetivamente en El país: "La epidemia se propaga", y La vanguardia: "El virus deja las calles desiertas", pero es transformado por El mundo en ataque explícito al Gobierno por la respuesta tardía al coronavirus: "45 días de imprevisión y pasividad que permitieron el zarpazo del virus. La gestión del Gobierno paso a paso. Los médicos alertaron el 30 de Enero y no hubo reacción". Reivindica (figura 4) el duelo oficial y refleja diferencias con El país en su relato del pacto entre el Gobierno y el Partido Popular.

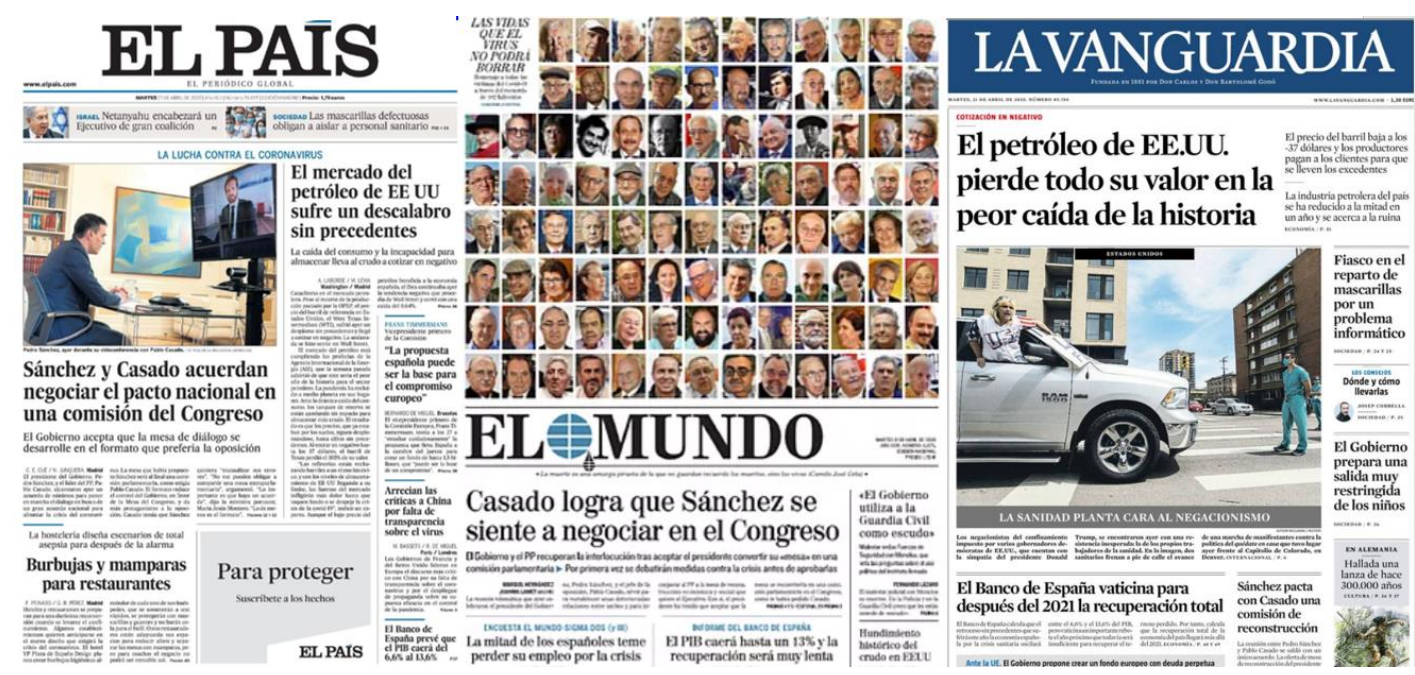

Figura 4. Portadas del 21 de abril de 2020.

Fuente: El país, El mundo, La vanguardia.

La vanguardia refleja, en ocasiones, enfoques más contundentes que los escogidos por los otros medios, sin desprenderse de los mismos una referencia perjudicial 0 beneficiosa a terceros, pero tampoco un tratamiento de gravedad justificado. 
La COVID-19 en la prensa española. Encuadres de alarma y tranquilidad en las portadas de El País, El Mundo y La Vanguardia

\section{DISCUSIÓN}

Como en esta, en anteriores crisis de pandemias ya se había demostrado que una información adecuada puede ayudar a solucionar los problemas, pero la saturación informativa puede resultar contraproducente (Cayón Nieto, 2009; Collinson, Khan y Heffernan, 2015). Contamos con estudios sobre el diferente papel de los medios de comunicación convencionales y las redes sociales, y su credibilidad (Austin, Fisher y Jin, 2012), e incluso, ya hace una década, se pueden encontrar estudios sobre el potencial de Twitter como sistema de rastreo y vigilancia para llevar a cabo estudios de infodemiología en la pandemia de gripe A de 2009-2010 (Chew y Eysenbach, 2010). En las pandemias se requiere que los medios de comunicación ayuden a minimizar los riesgos (Brown, 2020) y contribuyan a su solución con información veraz. Se trataría de combatir la desinformación de las fuentes menos fiables, nunca ocultando o disfrazando información para evitar, y mucho menos provocar, el pánico. Incluso se ha exigido a redes sociales como Facebook o Twitter, que habitualmente permiten desinformación política, que adopten posturas de mayor control con la desinformación médica.

Tanto en crisis sanitarias, como acontecimientos políticos y sociales de relevancia, una de las mayores preocupaciones de la investigación en comunicación ha sido siempre la ponderación del tono valorativo de las noticias (Zunino, 2016). Desde la teoría de la Agenda Setting y del Framing se ha abordado esta dimensión de análisis en múltiples trabajos sobre la cobertura mediática en nuestro país. Además de las campañas políticas, tema recurrente, se abordan aspectos como la inmigración (Igartua, 2007; Igartua et al., 2014); los grupos de exclusión social (FernándezFernández, 2012); el mundo árabe (Corralgarcía y Fernández-Romero, 2015); las vacunas (Cuesta-Cambra y Gaspar-Herrero, 2014; Cuesta-Cambra et al., 2019; Catalán-Matamoros y Peñafiel-Saiz, 2019); el desplazamiento de los refugiados (Sánchez Castillo, y Zarauza-Valero, 2020); el hambre en España (Marín-Murillo et al., 2020, o los procesos electorales (Pérez-Curiel et al., 2020).

En la información durante la pandemia del COVID-19, constatamos, al igual que Masip et al. (2020) un claro sesgo ideológico en los medios españoles, en evidente alineación y vinculación con los poderes económicos y políticos. También hemos comprobado cómo la información sensacionalista ha generado a veces una alarma social innecesaria, y que se ha aprovechado la pandemia para la difusión de numerosos contenidos falsos de tema político y gubernamental. (Salaverría et al., 2020).

A pesar de estar suficientemente demostrado el potencial de los medios tradicionales y de las redes sociales para la educación informal de la ciudadanía (Pereira et al, 2019), y de manera especial en situaciones de pandemia, los responsables de esos medios no consideran la educativa entre sus funciones prioritarias. Esta falta de sensibilidad no sería atribuible a los profesionales de la información, ya que, al analizar la influencia mediática, es preciso distinguir entre la práctica periodística, condicionada por la red de presiones, influencias y favores que se establece entre el poder económico, el poder político y la prensa (Jiménez-García, 2019), de los ideales y opiniones de los periodistas sobre sus funciones, que no suelen coincidir (Roses-Campos y Humanes, 
2019). También incidir en el reconocimiento de los medios de comunicación como actividad esencial durante la crisis de esta pandemia, consideración no muy coherente con el mapa de los ERTE en el sector de la comunicación (CNT, 2020). En cualquier caso, se detecta la necesidad de formar no sólo en competencia digital (Marta-Lazo et al., 2020), sino también en educación mediática a los profesionales de la información y la comunicación. Según De-Frutos-Torres et al (2020), las áreas de formación prioritarias no se sitúan en aspectos técnicos de los medios, sino en cuestiones éticas, deontológicas y en la prevención de riesgos.

\section{CONCLUSIONES}

En la mayoría de los estudios de comunicación sobre el encuadre o "framing" se confirma, como en la investigación aquí presentada, que los medios ofrecen unos contenidos sobre la realidad social que representan y presentan seleccionados según determinados intereses, y que, con la forma de presentar y representar, no sólo determinan la agenda pública, sino también las tendencias de opinión sobre la actualidad y el comportamiento de la ciudadanía.

A partir de los resultados obtenidos podemos concluir que el tratamiento de alarma no ha obedecido a la objetividad de los hechos noticiosos relatados sino a la ideología política que se asume al medio, ya que, ante los mismos hechos, El mundo incluye más noticias alarmistas y en la mitad de ellas aprovecha para criticar al Gobierno, mientras que La vanguardia lo hace en una de cada cuatro noticias y El país en una de cada seis.

Si bajo el recurso del alarmismo hay una intencionalidad de ataque al Gobierno, que se evidencia claramente en el diario El mundo, el enfoque de tranquilidad, vinculado a la actualidad sanitaria, no ha sido utilizado de forma partidista por ninguno de los diarios; aunque El país sea el medio que ha trasmitido más tranquilidad en sus portadas. Predomina el interés ideológico y político de los medios sobre la responsabilidad social incluso en situaciones de crisis sanitaria, y se da más cobertura a la gestión económica que a los aspectos sanitarios de la crisis.

No sin cierta nostalgia recordamos las funciones que el primer director de la BBC atribuyese a esta pionera institución: informar, educar y entretener. Tampoco, según nuestro estudio, se da demasiada importancia en la prensa a la función educativa de los medios ni a las repercusiones de la crisis sanitaria en educación, tema sobre el que solo se registran 9 noticias en los dos meses, sin enfoque significativo. Por ello, debemos concluir que, en muy contados casos, los medios asumen su función educativa.

En la introducción apuntábamos los desafíos que la crisis de la COVID-19 ha traído a los medios de comunicación para la que se ha dado en llamar "nueva normalidad". Además de la labor de investigación, se requiere recuperar la credibilidad con una información veraz y objetiva, tal vez solo posible con la independencia económica. En esta situación de precariedad, además de acciones concretas para asegurar el derecho 
La COVID-19 en la prensa española. Encuadres de alarma y tranquilidad en las portadas de El País, El Mundo y La Vanguardia

de la ciudadanía a una prensa libre y de servicio público, serán necesarias futuras investigaciones que traten de responder a estas preguntas: ¿Cuál va a ser la "nueva normalidad" de la prensa?; ¿sobrevivirán los medios a la crisis que ha traído la Covid19 garantizando la independencia informativa?; ¿qué responsabilidad social y educativa corresponde a los medios?

Permítannos una pregunta más a modo de reflexión final: La profesionalidad, ética, integridad y responsabilidad social que no parecen estar demostrando muchos dirigentes políticos en esta crisis de la COVID-19, ¿quién puede y debe exigírsela a los profesionales de la comunicación?

\section{REFERENCIAS}

AIMC (2019) Informe AIMC Ranking de diarios $3^{\text {a }}$ ola 2019. http://reporting.aimc.es/index.html\#/main/diarios

Amorós, M. (2020). Confianza social y desinformación. Las noticias están en guerra. Telos, 113, 18-21. Recuperado de https://telos.fundaciontelefonica.com/telos-113asuntos-de-comunicacion-fake-news-las-noticias-estan-en-guerra/

Ardèvol-Abreu, A. (2015): Framing o teoría del encuadre en comunicación. Orígenes, desarrollo y panorama actual en España. Revista Latina de Comunicación Social, 70, 423-450. doi: 10.4185/RLCS-2015-1053

Ardèvol-Abreu, A. (2016). Framing de las crisis humanitarias en los medios de comunicación españoles: Una aproximación inductiva / The Framing of Humanitarian Crises in the Spanish Media: An Inductive Approach. Reis: Revista Española De Investigaciones Sociológicas, 155, 37-53. doi: 10.5477/cis/reis.155.37

Ariel- Giménez, J., Andrea-Espinoza, J., Marcelo Vitale, F., Escalante Sánchez, M., Franceschi, M.J. y Cáneva, J. (2020). Coronavirus y desinformación: la otra pandemia. Buenos Aires: SEDICl. http://sedici.unlp.edu.ar/bitstream/handle/10915/94170/Documento completo.pdf?seq uence $=1$ \&isAllowed $=\mathrm{y}$

Arroyo-Barrantes, S., Rodríguez, M. y Pérez, R. (2009). Gestión de la información y comunicación en emergencias y desastres: Guía para equipos de respuesta. Washington, D.C.: https://www.paho.org/chi/index.php?option=com docman\&view=download\&category slug=guias-para-desastres\&alias=19-gestion-de-la-informacion-y-comunicacion-enemergencias- $y$-desastres\&ltemid $=1145$

Austin, L., Fisher, B. \& Jin, Y. (2012). Cómo las audiencias buscan información sobre la crisis: Explorando el modelo de comunicación de crisis mediada por medios sociales", Journal of Applied Communication Research, 40 (2), 188-207. doi: $\underline{10.1080 / 00909882.2012 .654498}$ 
La COVID-19 en la prensa española. Encuadres de alarma y tranquilidad en las portadas de El País, El Mundo y La Vanguardia

Branco, A. (2020). La otra cara del coronavirus: así es la batalla de los partidos políticos en Twitter. El Español, 8 (4). https://www.elespanol.com/espana/20200408/caracoronavirus-batalla-partidos-politicos-twitter/480703045 0.html

Brown, P. (2020) Studying COVID-19 in light of critical approaches to risk and uncertainty: research pathways, conceptual tools, and some magic from Mary Douglas, Health, Risk \& Society, 22 (1), 1-14. doi: 10.1080/13698575.2020.1745508

Canelón Silva, A. (2020). "The government narrative about COVI-19 in Venezuela: 'the emergency in a country in emergency'. "El relato de gobierno sobre el Covid-19en Venezuela: 'La emergencia en un país en emergencia'. Más Poder Local, 41, 39-41. http://maspoderlocal.es/ediciones/comunicacion-politica-Covid-19-no41/

Cano-Orón, L., Vengut-Climent, E., \& Moreno-Castro, C. (2020). Mental health images on the Internet: A Facebook and digital media content analysis in Spanish. Revista Prisma Social, 29, 240-259. https://revistaprismasocial.es/article/view/3338

Carter, M. J. (2013). The Hermeneutics of Frames and Framing: An Examination of the Media's Construction of Reality. SAGE Open. April-June 2013: 1-12. doi: $\underline{10.1177 / 2158244013487915}$

Casero-Ripollés, A. (2020). Impact of Covid-19 on the media system. Communicative and democratic consequences of news consumption during the outbreak. El profesional de la información, 29 (2), e290223. doi: 10.3145/epi.2020.mar.23

Catalán-Matamoros, D.; Peñafiel-Saiz, C. (2019): Medios y desconfianza en vacunas: un análisis de contenido en titulares de prensa. Revista Latina de Comunicación Social, 74, 786 -802. doi: 10.4185/RLCS-2019-1357

Cayón Nieto A. (2009). Comunicación de crisis en el marco de la preparación ante la pandemia de influenza en México: revisión de conceptos y estrategias. Revista de Administración Sanitaria, 7 (3), 501-16.

https://www.elsevier.es/es-revista-revista-administracion-sanitaria-siglo-xxi-261-articulocomunicacion-crisis-el-marco-preparacion-13141997

Chechik, S. (2020). Sensationalize or solutionize: Re-examining the role of news media in the age of COVID-19. The Daily Cardinal, 5-abril-2020.

https://www.dailycardinal.com/article/2020/04/sensationalize-or-solution-ize-reexamining-the-role-of-news-media-in-the-age-of-Covid-19

Chew, C.; Eysenbach, G. (2010). Pandemics in the age of Twitter: Content analysis of tweets during the 2009 H1N1 outbreak. PLoS one, 5 (11), e14118. doi: $\underline{10.1371 / \text { journal.pone.0014118 }}$ 
La COVID-19 en la prensa española. Encuadres de alarma y tranquilidad en las portadas de El País, El Mundo y La Vanguardia

Cinelli, M., Quattrociocchi, W., Galeazzi, A., Valensise, C. M., Brugnoli, E., Schmidt, A. L., Zola, P., Zollo, F. \& Scala, A. (2020) The COVID-19. Social Media Infodemic. arXiv:2003.05004 [cs.SI]. https://arxiv.org/pdf/2003.05004.pdf

Civeris, G., Watkins, E., Rashidian, N. \& Thielman, S. (2020). The Tow Center COVID19 Newsletter: Is the media the mirror or the antidote? Columbia Journalism Review. https://www.cjr.org/tow center/the-tow-center-Covid-19-newsletter-is-the-media-themirror-or-the-antidote.php

CNT (2020). El mapa de los ERTE en el sector de la comunicación. Sección de Prensa y Medios de Comunicación. Recuperado de https://madrid.cnt.es/wpcontent/uploads/2020/05/El-mapa-de-los-erte-en-el-sector-de-lacomunicaci\%C3\%B3n-3.pdf

Collinson, S.; Khan, K.; Heffernan, J. (2015). The Effects of Media Reports on Disease Spread and Important Public Health Measurements. PLOS ONE 10 (11), e0141423. doi: $\underline{10.1371 / \text { journal.pone. } 0141423}$

Corralgarcía, A. y Fernández Romero, C. (2015): Framing' y mundo árabe: la cobertura de la prensa española en torno a la revolución tunecina. Estudios sobre el Mensaje Periodístico, 21 (2), 793-811. doi: 10.5209/rev ESMP.2015.v21.n2.50885

Costa-Sánchez, C.; López-García, X. (2020). Comunicación y crisis del coronavirus en España. Primeras lecciones. El profesional de la información, 29 (3), e290304. doi: 10.3145/epi.2020.may.04

Crespo, I.; Garrido, A. (2020). The coronavirus pandemic: Crisis communication strategies. La pandemia del coronavirus. Estrategias de comunicación de crisis. Más poder local, 41 (4), 12-19. http://maspoderlocal.es/ediciones/comunicacion-politicaCovid-19-no41/

Cuesta Cambra, U. y Gaspar Herrero, S. (2014): La "reputación online" de la información de vacunas en internet. Historia y Comunicación Social, 19, Núm. Especial Febrero. 15-29. doi: 10.5209/rev HICS.2014.v19.45007

Cuesta-Cambra, U., Martínez-Martínez, L. \& Niño-González, J.I. (2019). An analysis of pro-vaccine and anti-vaccine information on social networks and the internet: Visual and emotional pattern". El professional de la información, 28 (2), e280217. doi: 10.3145/epi.2019.mar.17

De-Frutos-Torres, B., Collado-Alonso, R. y García-Matilla, A. (2020). El coste del smartphone entre los profesionales de la comunicación: análisis de las consecuencias sociales, laborales y personales. Revista Mediterránea de Comunicación/Mediterranean Journal of Communication, 11(1), 37-50. doi: 10.14198/MEDCOM2020.11.1.9 
La COVID-19 en la prensa española. Encuadres de alarma y tranquilidad en las portadas de El País, El Mundo y La Vanguardia

DeSteno, D. (2020) How Fear Distorts Our Thinking About the Coronavirus. The New York Times, $\quad$ Feb. 2020. https://www.nytimes.com/2020/02/11/opinion/international-world/coronavirus-fear.html

Dircom (2020). El papel de los medios de comunicación ante la pandemia del COVID19. Asociación de directivos de comunicación. http://www.dircom.org/actualidaddircom/item/10381-el-papel-de-los-medios-de-comunicacion-ante-la-pandemia-del$\underline{\text { Covid-19 }}$

Dobson, K. \& Knezevic, I. (2018). "Ain't Nobody Got Time for That!": Framing and Stereotyping in Legacy and Social Media. Canadian Journal of Communication, 43, 381-397. doi: $10.22230 / c j c .2018 v 43 n 3 a 3378$

Ducharme, J. (2020). "News Coverage of Coronavirus in 2020 is Very Different Than it Was For Ebola in 2018" TIME, February 7, 2020. https://time.com/5779872/coronavirus-ebola-news-coverage/

Elías, C. (2018). Fakenews, poder y periodismo en la era de la posverdad y hechos alternativos. Ámbitos. Revista Internacional de Comunicación, 40. https://idus.us.es/handle/11441/71888

Entman, R. M. (1993). Framing: Toward Clarification of a Fractured Paradigm. Journal of Communication, 43 (4), 51-58. doi: 10.1111/j.1460-2466.1993.tb01304.x

Entman, R. M. (2004). Projections of Power: Framing News, Public Opinion, and U.S. Foreign Policy (Studies in Communication, Media, and Public Opinion. Chicago \& London: The University of Chicago Press.

Euronews (2020). El coronavirus como arma política: España e Italia, la excepción europea. Noticias Euronews, 14-abril-2020. https://es.euronews.com/2020/04/14/elcoronavirus-como-arma-politica-espana-e-italia-la-excepcion-europea

Feo-Acevedo, C. y Feo-Istúriz, O. (2013). Impacto de los medios de comunicación en la salud pública. Impact of mass media in public health. Saúde em Debate, 37 (96), 8495. https://www.scielosp.org/pdf/sdeb/2013.v37n96/84-95/es

Fernández-Fernández, M. (2013): La diversidad y la discriminación en encuadres de El país, El mundo y ABC. Estudios sobre el mensaje periodístico, 19 (1), 91-106. doi: 10.5209/rev ESMP.2013.v19.n1.42509

Franceschi, M. J. y Caneva, J. (2020). Coronavirus y desinformación: la otra pandemia. Buenos Aires: SEDICI. http://sedici.unlp.edu.ar/handle/10915/94170

Gabbatt, A. (2016). Trump and Brexit: parallel campaigns built on fear, anger and charisma. The Guardian, 25 Jun 2016. https://www.theguardian.com/usnews/2016/jun/25/donald-trump-nigel-farage-us-election-brexit

Revista de Comunicación y Salud, 2020, Vol. 10, oㅡ 2, pp. 355-384 
La COVID-19 en la prensa española. Encuadres de alarma y tranquilidad en las portadas de El País, El Mundo y La Vanguardia

Gradoń, K. (2020). Crime in the time of the plague: fake news pandemic and the challenges to law-enforcement and intelligence community. Society Register, 4(2), 133-148. doi: $\underline{10.14746 / \text { sr.2020.4.2.10 }}$

Hao, K. \& Basu, T. (2020). The coronavirus is the first true social-media "infodemic". MIT Technology Review. https://www.technologyreview.com/2020/02/12/844851/thecoronavirus-is-the-first-true-social-media-infodemic/

Hernández-Orozco, H. G.; Ramiro-Mendoza, M. S.; Trejo-González, R. (2020). ¿Cuáles son las medidas de prevención contra el Novel Coronavirus (COVID-19)?. Which are the prevention measures against Novel Coronavirus (COVID-19). Revista Latinoamericana de Infectología Pediátrica, 33 (1), 4-6. doi: 10.35366/92380

Hu, Z., Yang, Z., Li, Q., Zhang, A. \& Huang, Y. (2020) Infodemiological Study on COVID-19 Epidemic and COVID-19. Infodemic. Preprints 2020, 2020020380. doi: 10.20944/preprints202002.0380.v2

Igartua, J. J. (ed) (2007). Medios de comunicación, inmigración y sociedad. Salamanca: Ediciones Universidad de Salamanca

Igartua, J. J., Cheng, L. y Muñiz, C. (2005a). Framing Latin America in the Spanish press. A cooled down friendship between two fraternal lands. Communications: The European Journal of Communication Research, 30(3), 359-372. http://diarium.usal.es/jigartua/files/2012/07/lgartua-ChengMu\%C3\%B1iz Communications-2005.pdf

Igartua, J. J., Cheng, L. y Muñiz, C. (2005b). La inmigración en la prensa española. Aportaciones empíricas y metodológicas desde la teoría del encuadre noticioso. Immigration in the Spanish press. Empirical and methodological findings in connection with the news framework theory. Migraciones, 17, 143-181. http://diarium.usal.es/iigartua/files/2012/07//gartua-et-al-Migraciones-2005.pdf

Igartua, J. J., Muñiz, C., Otero, J. A. y De la Fuente, M. (ed) (2014). La imagen de la inmigración en los informativos televisivos. Algo más que noticias. Salamanca: Ediciones Universidad de Salamanca

Jiménez-García, D. (2019). El director: secretos e intrigas de la prensa narrados por el exdirector de El mundo. Madrid: Libros del K.O.

Kim, Y. S. \& Chung; D. S. (2017). Anatomy of Front Pages: Comparison between The New York Times and other U.S. Major Metropolitan Newspapers. International Journal of Communication, 11(2017), 949-966. https://ijoc.org/index.php/ijoc/article/download/5898/1945 
La COVID-19 en la prensa española. Encuadres de alarma y tranquilidad en las portadas de El País, El Mundo y La Vanguardia

Kosmehl, M. (2020) Geopolitical symptoms of COVID-19: Narrative battles within the Eastern Partnership. Bertelsmann/Stiftung Policy Brief | 08.04.2020. [Policy Paper]. http://aei.pitt.edu/102700/1/EZ Flashlight 042020 ENG MK.pdf

Larivière, V., Shu, F. y Sugimoto, C. (2020). El brote de coronavirus (COVID-19) resalta serias deficiencias en la comunicación científica [Publicado originalmente en el LSE Impact Blog en marzo/2020] [online]. SciELO en Perspectiva, 2020. https://blog.scielo.org/es/2020/03/12/el-brote-de-coronavirus-Covid-19-resalta-seriasdeficiencias-en-la-comunicacion-cientifical

Lázaro-Rodríguez, P. y Herrera-Viedma, E. (2020). Noticias sobre Covid-19 y 2019nCoV en medios de comunicación de España: el papel de los medios digitales en tiempos de confinamiento. El profesional de la información, 29 (3), e290302. doi: 10.3145/epi.2020.may.02

Lerner, J. S.; Gonzalez, Roxana M.; Small, D. A; Fischhoff, B. (2003). Effects of fear and anger on perceived risks of terrorism: a national field experiment. Psychological Science, 14 (2). http://jenniferlerner.com/wp-content/uploads/2017/07/29.Effects-ofFear-and-Anger-on-Perceived-Risks-of-Terrorism.pdf

Lotero-Echeverri, G.; Romero-Rodríguez, L. M.; Pérez-Rodríguez, M. A. (2018). Factchecking vs. Fake news: Periodismo de confirmación como recurso de la competencia mediática contra la desinformación. Index.comunicación, 8(2), 295-316.

Marín-Murillo, F.; Armentia-Vizuete, J. L.; Marauri-Castillo, I \& Rodríguez-González, M. N. (2020). Food accessibility on digital press: framing and representation of hunger in Spain. Revista Latina de Comunicación Social, 75, 169-187. doi: 10.4185/RLCS2020-1421en

Marta-Lazo, C.; Rodríguez Rodríguez, J. M. \& Peñalva, S. (2020). Digital journalism competences. Systematic review of the scientific literature on new professional profiles of the journalist. Revista Latina de Comunicación Social, 75, 53-68. doi: $\underline{10.4185 / R L C S-2020-1416}$

Masip, P.; Aran-Ramspott, S.; Ruiz-Caballero, C.; Suau, J.; Almenar, E.; Puertas-Graell, D. (2020). Consumo informativo y cobertura mediática durante el confinamiento por el Covid-19: Sobreinformación, sesgo ideológico y sensacionalismo. El profesional de la información, 29 (3) e290312. doi: 10.3145/epi.2020.may.12

Mayo-Cubero, M. (2020). News sections, journalists and information sources in the journalistic coverage of crises and emergencies in Spain. El profesional de la información, 29 (2) e290211. doi: 10.3145/epi.2020.mar.11

Mayor-Ortega, L.; Pardo-Torregrosa, I. (4 abril 2020). Los partidos rivalizan por ver quién es más solidario con la sanidad. La vanguardia. https://www.lavanguardia.com/politica/20200404/48281920769/donaciones-partidoscongreso-parlament-salario-coronavirus-sanidad.html 
La COVID-19 en la prensa española. Encuadres de alarma y tranquilidad en las portadas de El País, El Mundo y La Vanguardia

Montesi, M. (2020). Las fake news sobre el COVID-19: ¿qué aprendemos de ellas? eLis. Preprint. http://hdl.handle.net/10760/39894

Muñiz-Muriel, C. (2014). La teoría del Framing es todavía una teoría emergente. Entrevista para la Universidad de Guadalajara. México. http://www.cucsh.udg.mx/noticia/la-teoria-del-framing-es-todavia-una-teoriaemergente-dr-carlos-muniz-muriel

Niemeyer, K. (2019) The front page as a time freezer: An analysis of the international newspaper coverage after the Charlie Hebdo attacks. Media, War \& Conflict, 12(2), 187-201. doi: $\underline{10.1177 / 1750635219839378}$

Nogués, G. (2018). Pensar con Otros: una guía de supervivencia en tiempos de posverdad. Buenos Aires: El Gato y la Caja.

Noguera Vivo, J. M. (2006). El Framing en la cobertura periodísticade la catástrofe: las víctimas, los culpables y el dolor. Sphera Pública, 6, 193-206. https://www.redalyc.org/articulo.oa?id=297/29700612

Norris, P.; Inglehart, R. (2019). Cultural Backlash: Trump, Brexit, and Authoritarian Populism. Cambridge: Cambridge University Press.

Noticias ONU (2020). La ONU lanza una iniciativa mundial contra la desinformación relacionada con el coronavirus. 21 de mayo. https://news.un.org/es/story/2020/05/1474802.

O'Connor, C.; Murphy, M. (2020). Going viral: doctors must tackle fake news in the Covid-19 pandemic. BMJ 2020; 369: m1587. doi: $\underline{10.1136 / \mathrm{bmj} . \mathrm{m} 1587}$

Pennycook, G.; McPhetres, J.; Zhang, Y.; Rand, D. G. (2020) Fighting COVID-19 misinformation on social media: Experimental evidence for a scalable accuracy nudge intervention. Preprint at PsyArXiv. doi: 10.31234/osf.io/uhbk9

Pereira, S.; Fillol, J.; Moura, P. (2019). El aprendizaje de los jóvenes con medios digitales fuera de la escuela. De lo informal a lo formal. Comunicar. Revista científica iberoamericana de comunicación y educación, 58, 41-50. doi: 10.3916/c58-2019-04

Pérez-Curiel, C., Jiménez-Marín, G. y García Medina, I. (2020). Influencia de agendas y estudio de framing en el marco electoral del Procés de Cataluña. Revista Latina de Comunicación Social, 75, 27-51. doi: 10.4185/RLCS-2020-1415

Poirier, W.; Ouellet, C.; Rancourt, M. A.; Béchard, J.; Dufresne, Y. (2020). (Un)covering the COVID-19 pandemic: Framing analysis of the crisis in Canada. Canadian Journal of Political Science, 53 (2), 365-371. doi: 10.1017/S0008423920000372 
La COVID-19 en la prensa española. Encuadres de alarma y tranquilidad en las portadas de El País, El Mundo y La Vanguardia

Qin, J. (2015). Hero on Twitter, traitor on news. How social media and legacy news frame Snowden. The international journal of press/politics, 20 (2) 166-184. doi: $\underline{10.1177 / 1940161214566709}$

Roses-Campos, S.; Humanes, M. L. (2019). Conflictos en los roles profesionales de los periodistas en España. Ideales y práctica. Comunicar: Revista científica iberoamericana de comunicación y educación, 58, 65-74. doi: 10.3916/c58-2019-06

Sádaba, T. (2001). Origen, aplicación y límites de la "teoría del encuadre" (framing) en comunicación. Comunicación y sociedad, 14 (2), 143-175. https://hdl.handle.net/10171/7975

Salaverría, R.; Buslón, N.; López-Pan, F.; León, B.; López-Goñi, I.; Erviti, M. C. (2020). Desinformación en tiempos de pandemia: tipología de los bulos sobre la Covid-19. El profesional de la información, 29, (3), e290315. doi: 10.3145/epi.2020.may.15

SEAE: Servicio Europeo de Acción Exterior (2020). Actualización del Informe especial del SEAE Breve evaluación de las narrativas y la desinformación en torno a la pandemia de la Covid-19. https://euvsdisinfo.eu/es/actualizacion-del-informeespecial-del-seae-breve-evaluacion-de-las-narrativas-y-la-desinformacion-en-torno-ala-pandemia-de-la-Covid-19/

Scheufele, D. A. (1999). Framing As a Theory of Media Effects. Journal of Communication. 49(1),103-122. doi: 10.1111/j.1460-2466.1999.tb02784.x

Semetko, H. y Valkenburg, P. (2000): Framing European Politics: a content analysis of press and television news, Journal of Communication, 50 (2), 93-109. doi: $\underline{10.1111 / j .1460-2466.2000 . t b 02843 . x}$

Slakoff, D. C.; Brennan, P. K. (2019) The Differential Representation of Latina and Black Female Victims in Front-Page News Stories: A Qualitative Document Analysis, Feminist Criminology, 14(4), 488-516. doi: https://doi.org/10.1177/1557085117747031.

Sukhankin, S. (2020). COVID-19 As a Tool of Information Confrontation: Russia's Approach. The School of Public Policy Publications, 13(3). https://ssrn.com/abstract=3566689

Tasnim, S.; Hossain, M.; Mazumder, H. (2020). Impact of rumors or misinformation on coronavirus disease. (Covid-19) in social media. SocArchiv. doi: $\underline{10.31235 / \text { osf.io/uf3zn }}$

Urbán, A. (2020) Hungary: Will the government use the coronavirus crisis to crush independent media? EJO: European Journalism Observatory. https://en.ejo.ch/mediapolitics/press-freedom/hungary-will-the-government-use-the-coronavirus-crisis-tocrush-independent-media 
La COVID-19 en la prensa española. Encuadres de alarma y tranquilidad en las portadas de El País, El Mundo y La Vanguardia

Van der Meer, T. \& Jin, Y. (2020). Seeking Formula for Misinformation Treatment in Public Health Crises: The Effects of Corrective Information Type and Source. Health Communication, 35 (5), 560-575. doi: 10.1080/10410236.2019.1573295

Wicke, P. y Bolognesi, M. (2020) Framing COVID-19: How we conceptualize and discuss the pandemic on Twitter. arXiv:2004.06986 [cs.CL]. https://arxiv.org/ftp/arxiv/papers/2004/2004.06986.pdf

WHO (2020). Coronavirus disease (COVID-2019) press briefings. https://www.who.int/emergencies/diseases/novel-coronavirus-2019/mediaresources/press-briefings

Zunino, E. (2016). La valoración de las noticias políticas en la agenda mediática: una propuesta metodológica para el análisis de contenido. Communication \& Society, 29(4), 235-254. https://dadun.unav.edu/bitstream/10171/41844/1/16.pdf

\section{AUTORES}

\section{Laura Picazo Sánchez}

Doctora en Ciencias de la Información por la Universidad Complutense de Madrid y licenciada en Comunicación Audiovisual. Profesora adjunta del área TIC en los Grados de Educación Infantil y Educación Primaria en la Universidad Internacional de Valencia, en formato $100 \%$ online. Imparte docencia en Educación Mediática y creación de materiales TIC para el aula de Primaria e Infantil. Especializada en el análisis de contenidos y fenómenos asociados al consumo de los mismos, especialmente en Internet, ahonda en repercusiones del uso de la red por parte de menores y en la Alfabetización mediática de los mismos, así como en la adaptación de las TIC en el aula de Primaria e Infantil. Es investigadora del proyecto Internética.

Orcid ID: https://orcid.org/0000-0002-1971-3671

Google Scholar: https://scholar.google.com/citations?user=tUtRSiOAAAAJ\&hl=en

ResearchID: AAF-9264-2019

\section{Belinda de Frutos Torres}

Doctora en Psicología por la Universidad Autónoma de Madrid en el Departamento de Psicología Social y Metodología. Profesora Titular de Universidad en la Universidad de Valladolid, imparte docencia en el grado en Publicidad y Relaciones Públicas, anteriormente trabajó en la Universidad San Pablo CEU e IE University. Especializada en los medios de comunicación de masas y su uso publicitario, su investigación está focalizada en las competencias digitales, medios interactivos: conectividad y redes sociales. Posee 2 sexenios de investigación reconocidos por CNEAI (último 20122018). Es investigadora del proyecto Internética.

Orcid ID: https://orcid.org/0000-0002-9391-8835

Google Scholar: https://scholar.google.es/citations?user=b e3MaEAAAAJ\&hl=es

ResearchID: AAR-1235-2020 
La COVID-19 en la prensa española. Encuadres de alarma y tranquilidad en las portadas de El País, El Mundo y La Vanguardia

\begin{abstract}
Alfonso Gutiérrez Martín
Es Doctor en Ciencias de la Educación por la Universidad Nacional de Educación a Distancia (U.N.E.D.) y MPhil (Master of Philosophy) por el Institute of Education de la Universidad de Londres. Actualmente es CAUN y profesor de Nuevas Tecnologías aplicadas a la Educación en la Universidad de Valladolid. (Facultad de Educación de Segovia). Ha participado como organizador, ponente y asistente en numerosas actividades de formación (cursos, congresos, seminarios, etc.) en España y en el extranjero, y ha participado en proyectos de investigación nacionales e internacionales. (https://alfguti.wixsite.com/alfonsogutierrez). Es IP del proyecto Internética.

Orcid ID: https://orcid.org/0000-0002-2288-9459

Google Scholar https://scholar.google.com/citations?user=2Sj-HP4AAAAJ\&hl=en

ResearchID: D-5528-2016
\end{abstract}

